\title{
PENGGUNAAN MEDIA TORSO PADA MATERI SISTEM PENCERNAAN MANUSIA TERHADAP KETUNTASAN BELAJAR SISWA KELAS V SDN DAYAH TANOH KABUPATEN PIDIE
}

\section{THE USE OF TORSO MEDIA IN THE MATERIAL OF THE HUMAN DIGESTIVE SYSTEM ON THE COMPLETENESS OF CLASS V STUDENTS ON SDN DAYAH TANOH PIDIE DISTRICT}

\author{
${ }^{1}$ Ruslaini, Universitas Iskandarmuda, Aceh, Indonesia. \\ ${ }^{2}$ Voenna Dara, Aceh, Indonesia. \\ ${ }^{1}$ ruslaini@unida-aceh.ac.id, ${ }^{2}$ rosenandajoel@yahoo.co.id
}

\begin{abstract}
ABSTRAK
Untuk menunjang tercapainya tujuan pengajaran IPA materi sistem pencernaan manusia diperlukan adanya suatu media yang tepat, seperti Media Torso. Tujuan penelitian ini adalah untuk mengetahui ketuntasan belajar siswa dengan penggunaan media torso pada materi sistem pencernaan manusia kelas V SD Negeri Dayah Tanoh Kecamatan Mutiara Kabupaten Pidie. Metode yang digunakan dalam penelitian ini yaitu True experimental design. Sampel dalam penelitian ini siswa kelas VA berjumlah 21 siswa sebagai kelas eksperimen, dan siswa kelas VB berjumlah 21 siswa sebagai kelas kontrol. Pengumpulan data dalam penelitian melalui ujian tulis. Analisis data hasil belajar siswa mengunakan rumus rata-rata (mean). Hasil analisis data hasil belajar siswa dengan menggunakan media torso pada materi sistem pencernaan manusia meningkat daripada siswa yang dibelajarkan dengan menggunakan media konvensional. Hasil nilai posttest kelas kontrol 68,1 dan hasil nilai posttest kelas eksperimen 82,1. Dengan demikian dapat disimpulkan penggunaan media torso terbukti mencapai ketuntasan belajar siswa pada materi sistem pencernaan manusia.
\end{abstract}

Kata Kunci: Media Torso, Sistem Pencernaan Manusia, Ketuntasan belajar 
PENGGUNAAN MEDIA TORSO PADA MATERI SISTEM PENCERNAAN MANUSIA TERHADAP KETUNTASAN BELAJAR SISWA KELAS V SDN DAYAH TANOH KABUPATEN PIDIE

Ruslaini, Voenna Dara
Jurnal Geuthèë: Penelitian Multidisiplin Vol. 03, No. 03, (Desember, 2020), pp. 487-499.

\begin{abstract}
To support the achievement of the objectives of teaching science in the human digestive system, it is necessary to have an appropriate medium, such as Torso Media. The purpose of this study was to determine the completeness of student learning using torso media on the material of the fifth grade human digestive system SD Negeri Dayah Tanoh, Mutiara District, Pidie Regency. The method used in this research is True experimental design. The sample in this study students of class VA totaling 21 students as the experimental class, and students of class VB amounted to 21 students as the control class. Data collection in research through written tests. Data analysis of student learning outcomes using the formula mean (mean). The results of data analysis on student learning outcomes using torso media on the human digestive system material increased than students who learned using conventional media. The result of the posttest score of the control class is 68.1 and the result of the posttest score of the experimental class is 82.1. Thus it can be concluded that the use of torso media is proven to achieve student learning completeness in the human digestive system material
\end{abstract}

Keywords: Torso Media, Human Digestive System, Complete learning 


\section{PENDAHULUAN}

Berdasarkan hasil observasi awal di SD Negeri Dayah Tanoh khususnya pada pembelajaran IPA materi sistem pencernaan manusia, diperoleh informasi bahwa ketersediaan media pembelajaran masih kurang, sehingga para pengajar menggunakan media secara minimal. Kenyataan yang sering terlihat adalah banyak pengajar menggunakan media pembelajaran seadanya dengan segala dampak terhadap pembelajaran. Selain itu siswa juga kurang memahami materi yang telah dijelaskan oleh guru. Keadaan seperti ini berlangsung setiap tahunnya dan materi yang diperoleh siswa sepenuhnya pada guru. Hal ini tentu berpengaruh pada hasil belajar yang didapatkan siswa yang akan menjadi tolak ukur keberhasilan dalam belajar dan sejauh mana sistem pembelajaran yang diberikan guru berhasil atau tidak. Nilai IPA pada materi sistem pencernaan manusia Kelas V Semester 1 Tahun 2017/2018 yang diperoleh siswa pada umumnya masih di bawah KKM yaitu 78, hanya $10 \%$ siswa yang nilai KKM nya 78 Media yang sering digunakan adalah media cetak sepeti buku paket, gambar-gambar, dan LKPD, Media torso hanya dijadikan sebagai pajangan di perpustakaan dan tidak digunakan oleh pengajar dalam menyampaikan materi pelajaran, begitu juga media audio visual yang menggunakan perangkat elektronik (komputer dan internet) masih belum dimanfaatkan.

Dalam pembelajaran IPA khususnya pada materi sistem pencernaan manusia, seharusnya dilakukan dengan menggunakan media torso. Media torso merupakan alat bantu yang tepat dalam menjelaskan materi-materi IPA sehingga kehadiran media tersebut dalam pembelajaran sangat mendukung proses penyampaian berbagai informasi dari guru dengan mudah dijelaskan kepada siswa. Lebih lanjut diungkapkan bahwa model torso tubuh manusia memberi pengamatan terbaik kepada para siswa mengenai letak serta ukuran dari organ tubuh yang sebenarnya. Torso sebagai alat peraga didesain sedemikian rupa sehingga mudah dipergunakan dalam proses belajar mengajar. Torso sangat mudah digunakan, guru dan siswa dapat mendeskripsikan dengan jelas nama, bentuk dan letak organ-organ tubuh manusia di depan kelas.

Media pembelajaran adalah alat yang dapat membantu proses belajar mengajar dan dapat digunakan untuk mempermudah siswa dalam mencapai suatu kompetensi, memperjelas suatu pesan serta mempermudah proses penyampaian materi pelajaran, sehingga dapat mencapai tujuan pembelajaran dengan lebih baik dan sempurna (Cecep, 2011:9). Media dalam pembelajaran dilihat dari jenisnya dibagi 
dalam tiga bagian yaitu; media audio, media visual dan media audio visual. Media berbasis visual (image atau perumpamaan) memegang peran yang sangat penting dalam proses belajar (Azhar Arsyad, 2005:91). Seperti hanya menampilkan gambar diam. Penggunaan media mempunyai hubungan yang sangat akurat terhadap peningkatan ketuntasan belajar siswa. Penggunaan media dalam proses-proses belajarmengajar dapat menghilangkan rasa bosan atau jenuh siswa dalam mengikuti pelajaran di sekolah. Dengan menggunakan media, maka kemampuan siswa dalam menangkap pelajaran akan semakin meningkat. Menurut (Rumampuk, 1998:19) Media pembelajaran dapat memberikan kontribusi berikut; penyampaian pesan pembelajaran dapat lebih terstandar, Pembelajaran dapat lebih menarik, Pembelajaran jadi lebih interaktif. dengan menerapkan teori belajar, Waktu pelaksanaan pembelajaran dapat diperpendek, Kualitas pembelajaran dapat di tingkatkan, Proses pembelajaran dapat berlangsung kapan pun dan di manapun di perlukan, Sikap positif siswa terhadap materi pembelajaran serta proses pembelajaran dapat di tingkatkan, Peran guru berubah ke arah yang positif

Media torso adalah salah satu media yang memberi pengamatan terbaik kepada murid mengenai letak serta ukuran dari organ tubuh yang sebenarnya (Sudjana, 2007:163). Belajar merupakan kegiatan anak didik untuk menerima, menanggapi, serta menganalisa bahan-bahan yang diberikan oleh pendidik. Berhasil tidaknya pencapaian tujuan pendidikan sangat tergantung pada bagaimana proses belajar yang dialami siswa sebagai anak didik. Belajar adalah suatu proses, suatu kegiatan dan bukan suatu hasil atau tujuan. Belajar bukan hanya mengingat akan tetapi lebih luas dari itu yaitu mengalami. Hasil belajar bukan suatu penguasaan hasil latihan melainkan pengubahan kelakuan (Oemar Hamalik, 2001:27). IPA sebagai bagian dari ilmu pengetahuan alam yang di dalamnya mempelajari konsep sistem pencernaan manusia merupakan salah satu bahan ajar yang dipelajari oleh siswa di sekolah. Sistem pencernaan manusia sangat penting untuk dipelajari sebab di dalamnya mempelajari proses pencernaan makanan. Makanan yang masuk ke dalam tubuh diolah dan diserap kemudian diedarkan ke seluruh tubuh dan dapat menjadi energi bagi kehidupan mahluk hidup itu sendiri.

Penggunaan media Torso sangat tepat pada dalam pembelajaran IPA materi sistem penceernaan manusia, karena siswa dapat mengamati langsung yang dijelaskan guru dan dapat menuntaskan hasil belajar siswa. Ketuntasan artinya hasil akhir dari suatu keberhasilan yang dicapai dalam suatu kegiatan dan menunjukkan kecakapan seseorang atau suatu bangsa. Ketuntasan belajar merupakan suatu bukti keberhasilan dari suatu usaha yang 
ditempuh melalui kegiatan belajar, sehingga dapat terlihat suatu perubahan pada diri individu sendiri baik dalam bentuk tingkah laku maupun cara-cara bertindak, mengambil keputusan yang tepat setelah proses belajar berlangsung. Ketuntasan belajar merupakan suatu periodisasi yang diperoleh melalui belajar. Keberhasilan belajar tergantung pada faktor-faktor yang mempengaruhi. Faktor-faktor yang mempengaruhi ketuntasan itu saling berhubungan antara satu dengan yang lain. Menururt (Nasution, 2003: 38dan48) ada beberapa faktor yang dapat mempengaruhi proses pembelajaran: "Faktor yang dapat mempengaruhi penguasaan seorang siswa terhadap satuan pelajaran yaitu: (1) Bakat untuk mempelajari sesuatu, (2) Mutu pengajaran, (3) Kesanggupan untuk memahami pengajaran, (4) Ketekunan, (5) Waktu yang tersedia untuk belajar.

Menurut (Masnur Muslich, 2008:18-19) ketuntasan belajar siswa adalah tingkat pemahaman siswa terhadap materi pelajaran yang telah diajarkan. Pembelajaran tuntas merupakan istilah yang diterjemahkan dari istilah "Mastery Learning". Mastery Learning atau belajar tuntas artinya penguasaan penuh. Penguasaan penuh ini dapat dicapai apabila siswa mampu menguasai materi tertentu secara menyeluruh yang dibuktikan dengan hasil belajar yang baik pada materi tersebut. Ketuntasan belajar merupakan suatu bukti keberhasilan dari suatu usaha yang ditempuh melalui kegiatan belajar, sehingga dapat terlihat suatu perubahan pada diri individu sendiri baik dalam bentuk tingkah laku maupun cara-cara bertindak, mengambil keputusan yang tepat setelah proses belajar berlangsung. Ketuntasan belajar juga dicapai oleh seseorang berdasarkan kemampuan potensial yang dimilikinya. Penguasaan hasil belajar oleh seseorang dapat dilihat dari prilakunya, baik perilakunya dalam penguasaan pelajaran, keterampilan balajar dan bekerja. Oleh karena itu, penting bagi guru untuk mengenal tingkat keberhasilan siswa agar dapat membantu kesulitan belajar siswa. Hal ini dapat diukur dengan pemberian dalam bentuk nilai atau skor dan hasil tes belajar siswa.

\section{METODE PENELITIAN}

Metode yang digunakan dalam penelitian ini adalah penelitian True experimental design (Suharsimi Arikunto, 2006:86). Penelitian True experimental design merupakan salah satu model penelitian yang dipandang sebagai eksperimen yang sebenarnya. Sampel dalam penelitian ini terdiri dari dua kelas 2 kelas yaitu: kelas VA sebanyak 21 siswa sebagai kelas eksperimen dan kelas V B sebanyak 21 siswa sebagai kelas kontrol. Teknik pengumpulan data dilakukan dengan menggunakan tes yang berbentuk multiple choise yang terdiri dari 25 soal. Tes yang diberikan berupa posttest untuk 
mengetahui efek sesudah pemberian perlakuan (Sugiyono, 2012:110).

Tabel 2 Desain penelitian katagori posttest-only control group design

\begin{tabular}{lll}
$\mathrm{R}_{1}$ & $\mathrm{x}$ & $\mathrm{O}_{2}$ \\
\hline $\mathrm{R}_{2}$ & $\mathrm{O}_{4}$
\end{tabular}

(Sugiyono, 2012:116)

$R_{l} \quad$ : Kelas eksperimen

$R_{2} \quad$ : Kelas kontrol

X : Perlakuan yang diberikan kepada kelas eksperimen dengan menggunakan media torso.

$\mathrm{O}_{2} \quad$ : Keefektifan hasil belajar siswa setelah diberi perlakuan.

$\mathrm{O}_{4} \quad$ : Keefektifan hasil belajar siswa tanpa diberi perlakuan.

\section{Teknik Analisis Data}

Data yang diperoleh dari hasil tes dianalisi dengan menggunakan nilai Rata-rata (mean), untuk mengetahui ada tidaknya ketuntasan hasil belajar siswa.. Ketuntasan belajar siswa pada kelas eksperimen dikatakan meningkat jika siswa dapat mencapai nilai rata- rata posttest lebih tinggi dari nilai rata- rata postest pada kelas kontrol.

Menurut (Sudjana, 2012:67) untuk menentukan kualifikasi hasil belajar yang dicapai oleh siswa dapat diketahui melalui nilai rata-rata yang dirumuskan sebagai berikut:

$$
\overline{\mathrm{x}}=\frac{\sum f i x i}{\sum f i}
$$

\section{Keterangan:}

$\bar{x} \quad$ :Nilai rata-rata (mean)
E fixi : Jumlah hasil perkalian antara masingmasing data dengan frekwensinya.

¿fi : Jumlah data.

\section{Hasil Penelitian dan Pembahasan}

Hasil belajar siswa merupakan hasil dari nilai posttest yang diperoleh siswa sebelum dan sesudah menggunakan media pembelajaran yaitu media torso pada materi sistem pencernaan pada manusia. Berdasarkan hasil analisis data diketahui bahwa hasil belajar siswa yang dibelajarkan dengan menggunakan media torso dapat meningkatkan hasil belajar siswa pada materi sistem pencernaan pada manusia kelas V A SD Negeri Dayah Tanoh lebih baik dari pada hasil belajar siswa yang dibelajarkan secara konvensional pada kelas VB yaitu dengan menggunakan buku paket.

Perbedaan hasil belajar siswa terlihat dari nilai rata-rata posttest kelas eksperimen dan kelas kontrol. Nilai rata-rata posttest yang diperoleh siswa yang dibelajarkan dengan menggunakan media torso yaitu 82,1 . Sedangkan nilai rata-rata yang diperoleh siswa dengan dibelajarkan menggunakan buku paket yaitu 68,1. Nilai posttest pada kelas kontrol dan kelas eksperimen dapat dilihat pada Tabel 1.

Tabel 1, Hasil posttest kelas kontrol dan kelas eksperimen

\begin{tabular}{|c|c|c|c|c|c|}
\hline \multirow{2}{*}{ No } & \multirow{2}{*}{$\begin{array}{c}\text { Kode } \\
\text { Siswa }\end{array}$} & \multicolumn{2}{|c|}{ Kelas Kontrol } & \multicolumn{2}{c|}{$\begin{array}{c}\text { Kelas } \\
\text { Eksperimen }\end{array}$} \\
\cline { 3 - 6 } & Posttest & KKM & Posttest & KKM \\
\hline 1 & XI & 70 & $\begin{array}{c}\text { Tidak } \\
\text { Tuntas }\end{array}$ & 86 & Tuntas \\
\hline 2 & X2 & 65 & $\begin{array}{c}\text { Tidak } \\
\text { Tuntas }\end{array}$ & 90 & Tuntas \\
\hline 3 & X3 & 66 & $\begin{array}{c}\text { Tidak } \\
\text { Tuntas }\end{array}$ & 84 & Tuntas \\
\hline 4 & X4 & 45 & $\begin{array}{c}\text { Tidak } \\
\text { Tuntas } \\
\text { Tidak }\end{array}$ & 75 & $\begin{array}{c}\text { Tidak } \\
\text { Tuntas }\end{array}$ \\
\hline 5 & X5 & 69 & 84 & Tuntas \\
\hline
\end{tabular}




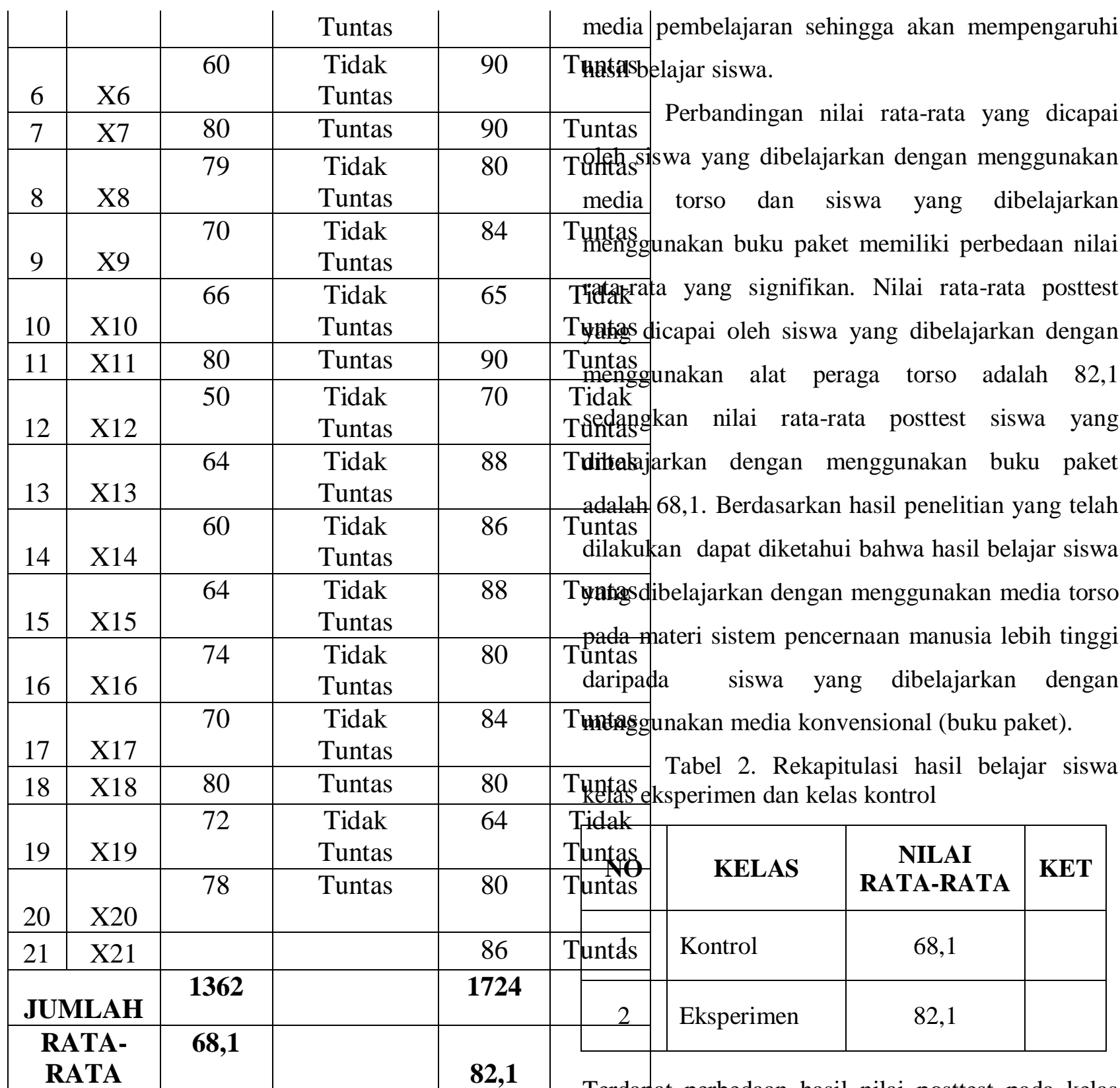

Sumber: Hasil pengolahan data 2019

Berdasarkan Tabel 1, diketahui bahwa terdapat perbedaan yang signifikan antara nilai posttest pada kelas eksperimen dan kelas kontrol. Nilai postest pada kelas eksperimen adalah 82,1 dan terdapat 3 siswa yang tidak mencapai nilai KKM, sedangkan nilai posttest pada kelas kontrol adalah 68,1 dan terdapat 5 siswa yang mencapai nilai KKM dari 21 siswa. Tidak tuntasnya hasil belajar siswa pada kelas kontrol disebabkan karena kurangnya
Terdapat perbedaan hasil nilai posttest pada kelas kontrol dan eksperimen. Untuk lebih jelasnya dapat dilihat pada grafik berikut ini:

Grafik 1 Nilai rata-rata hasil belajar siswa sesudah pemberian posttest kelas kontrol dan kelas eksperimen. 


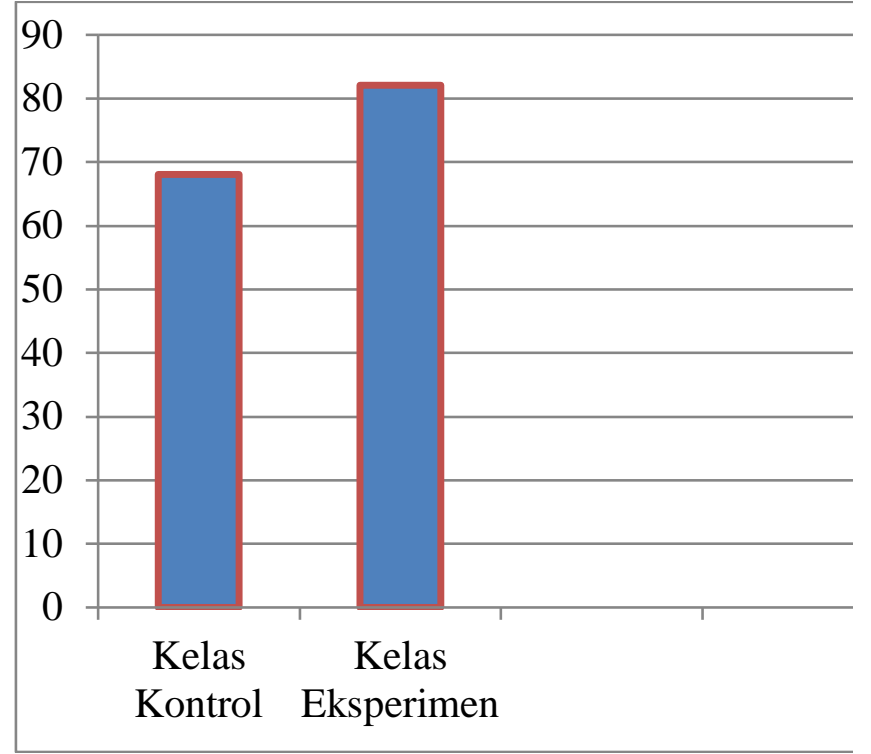

Data hasil belajar siswa dianalisis dengan menggunakan rumus rata-rata (mean) untuk mengetahui ada tidaknya peningkatan hasil belajar siswa. Hasil analisis data yang diperoleh dari hasil belajar siswa kelas eksperimen dan siswa kelas kontrol.

$$
\begin{aligned}
& \text { Kelas eksperimen } \\
& \overline{\mathrm{x}}=\frac{\sum f i x i}{\sum f i} \\
& =\frac{1362}{21} \\
& =82,1 \\
& \overline{\mathrm{X}}=\frac{\sum f i x i}{\sum f i} \\
& =\frac{1724}{20} \\
& =68,1
\end{aligned}
$$

Uraian di atas menunjukkan hasil belajar siswa yang dilakukan dengan menganalisis nilai rata-rata kedua kelas tersebut menunjukkan hasil yang signifikan. Hasil belajar siswa dengan menggunakan media torso meningkat atau lebih baik, hal ini didukung oleh penelitian yang dilakukan oleh Oktavia Putri Rahmawati (2014) bahwa penggunaan media torso dapat meninggkatkan hasil belajar siswa. Data tersebut menunjukkan bahwa nilai rata-rata yang diperoleh antara kedua kelas tersebut memiliki perbedaan yang signifikan, dalam arti nilai rata-rata kelas eksperimen lebih tinggi dibandingkan dengan kelas kontrol, ini dikarenakan pada kelas eksperimen diberikan perlakuan dengan menggunakan media torso, sedangkan pada kelas kontrol diberikan perlakuan dengan menggunakan buku paket.

\section{Pengujian Hipotesis}

Pengujian hipotesis dalam penelitian ini menggunakan rumus rata-rata (mean). Jadi hasil belajar siswa yang dibelajarkan dengan penggunaan media torso pada materi sistem pencernaan pada manusia meningkat dibandingkan hasil belajar siswa yang dibelajarkan dengan menggunakan buku paket.

\section{Simpulan}

Berdasarkan hasil penelitian yang telah dilakukan di SD Negeri Dayah Tanoh, dengan penggunaan media torso pada materi sistem pencernaan manusia siswa kelas V SD Negeri Dayah Tanoh Kabupaten Pidie dapat meningkatkan ketuntasan belajar siswa. 


\section{Daftar Pustaka}

Admaja Purwa Prawira. 2012. Psikologi Pendidikan Dalam Perspektif Baru. Jakarta: aR-Ruzz Media.

Agus, riyanto. 2011. Aplikasi Metodelogi Penelitian Kesehatan. Nuha: medika yogyakarta.

Arikunto, Suharsimi. 2013. Prosedur Penelitian Suatu Pendekatan Praktek. Jakarta: Rineke Cipta.

Arsyad, Azhar. 2005. Media Pembelajaran. Jakarta: Raja Grafindo Persada.

2013. Media Pembelajaran. Jakarta: Raja Grafindo Persada.

Campbell. 2004. BIOLOGI Jilid 3. Jakarta: Erlangga.

Cecep Kustandi \& Bambang Sutjipto. 2011. Media Pembelajaran Manual dan Digital. Bogor: Ghalia Indonesia.

Hamalik, Omar. 2001. Proses Belajar Mengajar. Jakarta: Bumi Aksara.

Harjanto. 2005. Perencanaan Pengajaran, Jakarta: Rineka Cipta.

Irianto, Kus. 2008. Struktur dan Fungsi Tubuh Manusia. Jakarta : Yrama widya.

Kustandi Cecep \& Bambang Sutjipto. 2011. Media Pembelajaran Manual dan Digital. Bogor: Ghalia Indonesia.

Nasution, S. 2003. Berbagai Pendekatan Dalam Proses Belajar dan Mengajar. Jakarta: Bumi Aksara.

Oktavia Putri Rahmawati. 2014. "PENGGUNAAN MEDIA TORSO UNTUK MENINGKATKAN HASIL BELAJAR SISWA DI SEKOLAH DASAR”. Jurnal Teknologi Pendidikan.

Sanjaya, wina. 2012. Strategi pembelajaran berorientasi standar proses pendidikan. Jakarta: kencana.

Sardirman. 2006. Interaksi dan Motivasi Belajar Mengajar. Jakarta: PT. Remaja Rosdakarya.

Sudjana, Nana. 2007. Penelitian Hasil Proses Belajar Mengajar. Bandung: Remaja Rosdakarya 2012. Penelitian Hasil Proses Belajar Mengajar. Bandung: Remaja Rosdakarya

Syaifuddin. 2006. Anatomi dan Fisiologi Manusia untuk Mahasiswa Keperawatan. Jakarta : Buku Kedokteran EGC.

Syamsuri, Istamar dkk. 2016. IPA BIOLOGI. Jakarta: Erlangga.

Wijaya Jati. 2007. Aktif Biologi. Jakarta: Ganeca Exac. 